\title{
PERMANENTS, DETERMINANTS, AND GENERALIZED COMPLEMENTARY BASIC MATRICES
}

\author{
Miroslav Fiedler, Frank J. Hall and Mikhail Stroev
}

Abstract. This paper answers the questions posed in the article "A note on permanents and generalized complementary basic matrices", Linear Algebra Appl. 436 (2012), by M. Fiedler and F. Hall. Determinant and permanent compound products which are intrinsic are also explored, along with extensions to total unimodularity.

Mathematics subject classification (2010): 15A15, 15A23.

Keywords and phrases: Factorization, GCB-matrix, permanent, intrinsic product.

\section{REFERENCES}

[1] V. S. AL'PinA AND Y. A. AL'PIn, Permanental compound matrices and Schneider's Theorem, Journal of Mathematical Sciences 132 (2) (2006), 147-152.

[2] R. A. BRualdi And H. J. Ryser, Combinatorial Matrix Theory, Cambridge University Press, Cambridge, 1991.

[3] J. E. CoHEn, Supermultiplicative inequalities for the permanent of nonnegative matrices, Mathematics Magazine 65 (1) (1992), 41-44.

[4] G. M. ENGEL AND H. SCHNEIDER, Inequalities for determinants and permanents, Lin. Multilin. Algebra 1 (1973), 187-201.

[5] M. FIEDLER, Complementary basic matrices, Linear Algebra Appl. 384 (2004), 199-206.

[6] M. FIEDLER, Intrinsic products and factorizations of matrices, Linear Algebra Appl. 428 (2008), $5-13$.

[7] M. FIEDlER AND F. J. HALL, Some inheritance properties for complementary basic matrices, Linear Algebra Appl. 433 (2010), 2060-2069.

[8] M. Fiedler And F. J. Hall, G-matrices, Linear Algebra Appl. 436 (2012), 731-741.

[9] M. FIEDLER AND F. J. HALL, A note on permanents and generalized complementary basic matrices, Linear Algebra Appl. 436 (2012), 3553-3569.

[10] M. Marcus And H. Minc, A Survey of Matrix Theory and Matrix Inequalities, Allyn and Bacon, Boston, 1964. 